\title{
Liposarcoma in the spermatic cord presenting as an inguinal swelling
}

\author{
Maria Feldborg Bruun Andersen ${ }^{1}$, Mikkel Fode ${ }^{1}$, Anette Pedersen Pilt ${ }^{2}$, Nessn Htum Majeed Azawi ${ }^{1}$ \\ ${ }^{1}$ Deptartment of Urology, ${ }^{2}$ Department of Pathology, Zealand's Hospital University Roskilde, Roskilde, Denmark \\ Correspondence to: Maria Feldborg Bruun Andersen, MD. Zealand's University Hospital Roskilde, Pilehoej 6D, st, DK-3460 Birkeroed, Denmark. \\ Email: marias@dadlnet.dk.
}

\begin{abstract}
Liposarcoma in the spermatic cord is a rare condition with an incidence of 1 per 2.5 million. The condition can present as paratesticular pain and a quick diagnosis is important in order to ensure proper treatment and to improve the prognosis. We describe a case of a 69-year-old man who suffered from long-lasting swelling in the inguinal area and experienced increasing pain through a period of 2 weeks. Due to increasing pain and fast growing swelling, an exploration of the inguinal area was performed and peroperatively a tumour in the spermatic cord was found. Subsequent histological examination revealed a de-differentiated liposarcoma.
\end{abstract}

Keywords: Sarcoma inguinal mass

Submitted Aug 10, 2017. Accepted for publication Aug 24, 2017.

doi: $10.21037 /$ tau.2017.08.18

View this article at: http://dx.doi.org/10.21037/tau.2017.08.18

\section{Introduction}

Retroperitoneal tumours are classified according to their origin into mesodermal, neurogenic, and germinative tumours (1). Liposarcomas are of mesodermal origin and are derived from fat tissue. Primary liposarcomas in the retroperitoneum are aggressive and rare with an incidence rate of 1 per 2.5 million (2). If they are diagnosed early, localized tumours can be successfully treated with surgical resection and possibly adjuvant oncological therapy, according to the histology (3). In such cases, the five-year survival for high grade tumours in the spermatic cord in adults is approximately $75 \%(1,4)$. However, lifelong follow-up is recommended after treatment, as late recurrences have been recorded (5).

\section{Case presentation}

A 69-year-old man was referred to the Department of Urology, Roskilde Hospital on suspicion of malignancy because of increasing scrotal swelling in spite of antibiotic treatment.
On clinical examination a painless process along the spermatic cord was palpated. It was free of the testicle and did not stretch into the inguinal canal. A computerized tomography (CT) scan was performed and this revealed a $4.4 \mathrm{~cm}$ tumour distally in the inguinal canal stretching toward the epididymis. Biochemically, alpha-foetoprotein, s-human chorionic gonadotropin and lactate dehydrogenase levels were all within normal limits.

The patient was admitted for further observation of the swollen area, but his clinical condition worsened and the pain and swelling increased rapidly. A surgical exploration of the inguinal area and scrotum was performed. Peroperatively a firm $6 \mathrm{~cm} \times 6 \mathrm{~cm}$ process in the spermatic cord was found. To ensure negative margins, a wide resection was performed (Figure 1). Histological examination showed the presence of lipoblast cells and the analysis for classification determinant 34 (CD34) showed positive result suggesting a liposarcoma. An analysis for mouse double minute 2 homolog (MDM2) and antigen $\mathrm{Ki}-67$ test was done, both of them were positive resulting in the diagnose of a de-differentiated liposarcoma in the spermatic cord (Figure 2). 


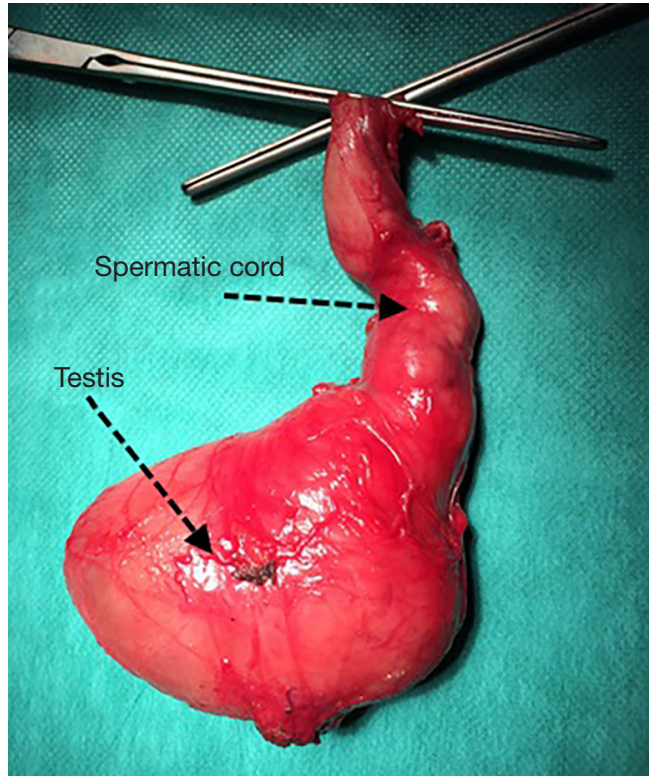

Figure 1 Specimen macroscopically. Spermatic cord with tumour and testicular tissue.

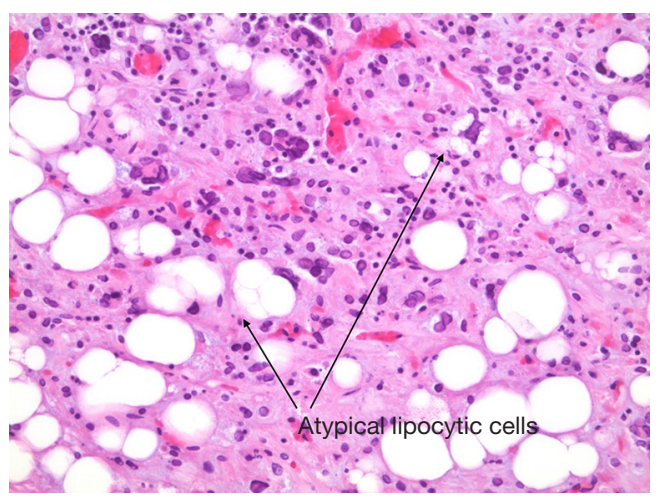

Figure 2 Histological specimen from tumour showing atypical cells and lipoblast. Hematoxilin-Eosin, $\times 200$.

A thoracic postoperative CT scan showed no signs of metastasis and the patient was referred to a highly specialised multidisciplinary team to receive adjuvant radiation therapy. The total follow-up period is currently 8 months with no signs of recurrence.

\section{Discussion}

Liposarcomas in the spermatic cord were first described in 1952, and there are only approximately 200 cases described in the literature $(6,7)$.

Due to the high fat content, it can be difficult to distinguish lipomas from liposarcomas with ultrasound and CT scans. Therefore, the preferred method for the diagnosis of these fatty structures is magnetic resonance imaging (MRI). For differential diagnostic purposes, the cancer markers alpha fetoprotein, s-hCG, and lactate dehydrogenase are used to identify possible germ cell tumours.

The histological diagnosis of liposarcomas is divided into three categories according to their cytogenetic characteristics in either well-differentiated or de-differentiated: (I) myxoid and (II) round cell tumours often have high incidence and are satisfactorily treated with resection with a wide margin; (III) pleomorphic liposarcomas are low-differentiated and highly malignant and the treatment is radical resection.

There is no gold standard for the treatment of liposarcomas in the spermatic cord, however there is evidence to support that radical surgery is the most important factor in the treatment. Provided the tumour is well-differentiated and defined, it is possible to give adjuvant radiotherapy in order to minimize the risk for local recurrence, however there is no evidence that this improves the prognosis. The patients should attend lifelong follow-up with clinical evaluation and CT scan of the thorax and abdomen, since recurrence of liposarcomas has been seen up to 15 years after the initial treatment (5).

\section{Acknowledgements}

None.

\section{Footnote}

Conflicts of Interest: The authors have no conflicts of interest to declare.

Informed Consent: Written informed consent was obtained from the patient for publication of this manuscript and any accompanying images.

\section{References}

1. Vagnoni V, Brunocilla E, Schiavina R, et al. Inguinal canal tumors of adulthood. Anticancer Res 2013;33:2361-8.

2. Zhang WD, Liu DR, Que RS, et al. Management of retroperitoneal liposarcoma: a case report and review of the literature. Oncol Lett 2015;10:405-9.

3. Tan MC, Brennan MF, Kuk D, et al. Histology-based classification predicts pattern of recurrence and improves 
risk stratification in primary retroperitoneal sarcoma. Ann Surg 2016;263:593-600.

4. Coleman J, Brennan MF, Alektiar K, et al. Adult spermatic cord sarcomas: management and results. Ann Surg Oncol 2003;10:669-75.

5. Ballo MT, Zagars GK, Pisters PW, et al. Spermatic cord sarcoma: outcome, patterns of failure and management. J

Cite this article as: Andersen MF, Fode M, Pilt AP, Azawi NH. Liposarcoma in the spermatic cord presenting as an inguinal swelling. Transl Androl Urol 2017;6(5):978-980. doi: 10.21037/ tau.2017.08.18
Urol 2001;166:1306-10.

6. Schwartz SL, Swierzewski SJ 3rd, Sondak VK, et al. Liposarcoma of the spermatic cord: report of 6 cases and review of the literature. J Urol 1995;153:154-7.

7. Li F, Tian R, Yin C, et al. Liposarcoma of the spermatic cord mimicking a left inguinal hernia: a case report and literature review. World J Surg Oncol 2013;11:18. 